\title{
Genetic Variation for Virulence and Resistance in the Wheat-Mycosphaerella graminicola Pathosystem III. Comparative Seedling and Adult Plant Experiments
}

\author{
Gert H. J. Kema and Cor H. van Silfhout
}

DLO-Research Institute for Plant Protection (IPO-DLO), P.O. Box 9060, 6700 GW Wageningen, the Netherlands. Accepted for publication 24 October 1996.

\section{ABSTRACT}

Kema, G. H. J., and van Silfhout, C. H. 1997. Genetic variation for virulence and resistance in the wheat-Mycosphaerella graminicola pathosystem. III. Comparative seedling and adult plant experiments. Phytopathology 87:266-272.

Fourteen Dutch Mycosphaerella graminicola isolates were studied for their virulence to 22 wheat cultivars in the seedling stage in an experiment set up as a completely randomized block design with three repetitions. Isolate $\times$ cultivar interactions were highly significant. Cluster analyses were applied to select three isolates with significantly different virulence characteristics for both disease parameters. These were retested in the seedling stage and used to inoculate two field experiments that were planted according to a split plot design in 1992 and 1995. Overhead inoculations were conducted after flowering to avoid the effects of plant height; hence, these experiments were intended as monocyclic tests for virulence differences between the isolates. Significant isolate $\times$ cultivar interactions were detected in each experiment, demonstrating specificity in the wheat $M$. graminicola pathosystem in the adult plant stage under field conditions. The reproducibility of the adult plant data was high. Genetic differences among the isolates were additionally demonstrated by randomly amplified polymorphic DNA (RAPD) patterns, which also showed that no significant contamination of the inoculated plots with the natural M. graminicola population had occurred. Rank correlations between seedling and adult plant data were significant for $M$. graminicola isolates IPO323 and IPO290, but not for isolate IPO001. Hence, evaluation of resistance and virulence may require seedling, as well as adult plant, tests.

Additional keywords: host-pathogen interaction, Septoria tritici.
Septoria tritici leaf blotch is a disease of bread wheat and durum wheat, Triticum aestivum L. and T. turgidum ssp. durum L., respectively, that is of increasing importance in regions with a temperate climate, including western Europe (26). It is caused by Mycosphaerella graminicola (Fuckel) J. Schröt. in Cohn (anamorph: Septoria tritici Roberge in Desmaz.), an ascomycete that was recently found to have a bipolar heterothallic mating system (17). The disease is characterized by necrotic blotches that develop after massive cell collapse and eventually contain variable numbers of pycnidia, the asexual fructifications (18).

Ascospores are considered to be responsible for the establishment of the disease in autumn and winter $(28,33)$. However, their possible role in disease progress during the growing season was only recently discussed by Kema et al. (17), who demonstrated the ability of M. graminicola to complete several sexual cycles per year. Hence, $M$. graminicola might be responsible for the establishment of different founder populations throughout the season, which is in accord with the vast genetic variation for molecular and virulence markers $(3,15,16,20,21)$.

Specificity in the wheat- $M$. graminicola pathosystem has been debated for more than 20 years, since the first claim for physiologic specialization in the pathogen (10). Recently, Kema et al. $(15,16)$ provided circumstantial evidence for adaptation to host species and cultivars and suggested that the lack of consensus about this subject in the literature might have been because of differences in methodologies and environmental conditions. In addition, studies on genetic variation for virulence in $M$. graminicola were entirely based on seedling experiments under controlled

Corresponding author: G. H. J. Kema; E-mail address: g.h.j.kema@ipo.dlo.nl

Publication no. P-1997-0124-01R

(C) 1997 The American Phytopathological Society conditions $(11,12,15,16,36)$. Translation of such data to adult plants under field conditions, however, requires validation by comparative experiments.

We report the occurrence of cultivar $x$ isolate interactions in comparative seedling versus adult plant experiments that were conducted under controlled and field conditions, respectively.

\section{MATERIALS AND METHODS}

Plant materials. Twenty-two bread wheat cultivars were used to study genetic variation for resistance in the seedling stage. The same cultivars were used in a field experiment in 1992, whereas a subset of five cultivars was selected for a field experiment in 1995 (Table 1). The majority of the cultivars has been of commercial importance in the Netherlands since the early 1930s.

M. graminicola isolates. Fourteen Dutch M. graminicola isolates, selected over a period of approximately 20 years, were used to study genetic variation for virulence as expressed on seedlings (Table 2). Two disease parameters were considered in seedling and adult plant experiments: $N$, the percentage of necrotic leaf area caused by $M$. graminicola, and $P$, the percentage of the same leaves covered with pycnidia, enabling us to identify responses with different levels of both parameters. Cluster analyses were applied to select a subset of three isolates (IPO001, IPO290, and $I P O 323)$ that significantly differed from each other for both virulence characteristics. These isolates were used to inoculate two field experiments in 1992 and 1995, respectively.

Experimental design and data analyses. Inoculum preparation, experimental conditions, and procedures were similar to those described by Kema et al. $(15,16)$. The seedling experiment was conducted according to a randomized block design with three repetitions. The selected subset of isolates was retested once to check the repeatability of the observed data. 
The field experiments were conducted according to a split plot design with two replications. In both experiments, $M$. graminicola isolates and a noninoculated control were randomly allocated to main plots, and the cultivars were randomized within these main plots. The cultivars were planted in small plots $\left(9 \mathrm{~m}^{2}\right.$, containing $2-\mathrm{m}^{2}$ wheat fields) that were separated by $3 \mathrm{~m}$ of winter barley within each treatment and $6 \mathrm{~m}$ of winter barley between the treatments. The field experiments were subjected to standard agronomical practices, except fungicide treatments. The experiments were set up as monocyclic tests for interactions in the adult plant stage and were, therefore, inoculated after anthesis at growth stage 61 (37) to avoid the effects of plant height $(2,8)$. To provide favorable relative humidities (RHs) in the crop, an irrigation system was installed. Before the first inoculation, the system was switched on for $24 \mathrm{~h}$ at an interval of $1 \mathrm{~min}$ of irrigation every quarter of an hour and was adjusted later to an interval of 1 min of irrigation every $30 \mathrm{~min}$ during day time.

The 1992 field experiment was inoculated on 4 June $\left(2.3 \times 10^{6}\right.$ spores $\left.\mathrm{ml}^{-1}\right), 9$ June $\left(2.0 \times 10^{6}\right.$ spores $\left.\mathrm{ml}^{-1}\right)$, and 22 June $(1.1 \times$ $10^{6}$ spores $\mathrm{ml}^{-1}$ ). On 29 June, random samples from 10 to 15 plants of each plot in each treatment were taken for disease assessment on flag and second leaves of the main culms. The 1995 field experiment was inoculated on 24 May $\left(1.0 \times 10^{6}\right.$ spores $\left.\mathrm{ml}^{-1}\right)$, 29 May $\left(0.2 \times 10^{6}\right.$ spores $\left.\mathrm{ml}^{-1}\right)$, and 2 June $\left(0.12 \times 10^{6}\right.$ spores $\left.\mathrm{ml}^{-1}\right)$. On 22 June, random samples from 10 to 15 plants of each plot in each treatment were taken for disease assessment on flag and second leaves of the main tillers. The first and second inoculations were conducted under favorable weather conditions, providing a natural humid environment for at least $48 \mathrm{~h}$.

All statistical analyses were conducted by the Genstat 5 statistical package (Lawes Agricultural Trust, Rothamsted, United Kingdom), using generalized linear models (GLMs) with logit link and variance function proportional to $M(100-M)$, in which $M$ is the mean disease parameter; nonparametric procedures and cluster analyses were as described by Kema et al. $(15,16)$. The cluster analyses were performed on complete seedling data sets, whereas

TABLE 1. Pedigree and cultivation period in the Netherlands of 22 bread wheat cultivars that were used to study genetic variation for virulence in 14 Dutch Mycosphaerella graminicola isolates in seedling and adult plant experiments

\begin{tabular}{|c|c|c|}
\hline Cultivar & Pedigree & $\begin{array}{l}\text { Cultivation } \\
\text { period }\end{array}$ \\
\hline Carsten V & Dikkop/Criewener 104 & $1932-1957$ \\
\hline Heines VII & Hybride à courte paille/Svälof's Kronen & $1950-1967$ \\
\hline Felix & Tassilo/Carsten//Carsten/Marquillo & $1958-1973$ \\
\hline Manella & Alba/Heines VII & $1964-1980$ \\
\hline Joss Cambier & Heines VII/Tadepi & $1968-1978$ \\
\hline Lely & Cebeco 30/Flevina & 1969-1979 \\
\hline Clement $^{\mathrm{a}}$ & $\begin{array}{l}\text { Hope/Timstein//3xHeines VII/3/Riebesel 57- } \\
\text { 41/2xHeines VII/4/Cleo }\end{array}$ & $1972-1980$ \\
\hline Okapi $^{\mathrm{a}}$ & Capelle Desprez/Carsten's Winterweizen III & $1975-1990$ \\
\hline Arminda & Carsten's $854 /$ Ibis & $1976-1990$ \\
\hline Obelisk & Selection from a composite cross of 36 cultivars & $1985-1993$ \\
\hline Taurus & RPB 181-70D/Griffin & $>1987$ \\
\hline Ritmo & Hobbit/1320//Wizzard/3/Marksman/Virtue & $>1992$ \\
\hline Estica & Arminda/Virtue & $>1993$ \\
\hline Bussard $^{b}$ & Kranich/Maris Huntsman//Monopol & $\ldots$ \\
\hline Vivant $^{\mathrm{a}}$ & Boxer/Gawain & $>1993$ \\
\hline Rektor $^{\mathrm{b}}$ & Kormoran/Monopol & $\ldots$ \\
\hline Renan $^{\mathrm{b}}$ & $\begin{array}{l}\text { Mironovskaya 808/Maris Huntsman// } \\
\text { VPM/Moisson//Courtot }\end{array}$ & $\cdots$ \\
\hline Hereward $^{\mathrm{a}}$ & Norman's sib/Disponent & $>1993$ \\
\hline Bon Fermier ${ }^{b}$ & Gros bleu/Blé seigle & $\ldots$ \\
\hline Veranopolis $\mathrm{b}, \mathrm{c}$ & TCO/B2017-37 & $\ldots$ \\
\hline Kavkaz $^{\mathrm{a}, \mathrm{b}}$ & Lutescens 314H147/Bezostaja 1 & .. \\
\hline SVP $72017^{d}$ & Marzotto//Dippes Triumph/Mironovskaya 80 & $\ldots$ \\
\hline
\end{tabular}

a Cultivars employed in field experiment 1995.

${ }^{\mathrm{b}}$ Cultivar that has not been cultivated in the Netherlands.

c Brazilian spring wheat.

d Experimental wheat line. the GLM on seedling data was restricted to the selected subset of isolates that was used to inoculate the field experiment. Since disease levels in the control plots were negligible, corrections were unnecessary. Statistical analyses were restricted to data collected from the flag leaves, since inoculum deposition on the second leaf layer was partly intercepted by the flag leaves, which is a factor difficult to account for. GLMs with blocks, cultivars, isolates, and the interaction between cultivars and isolates as explanatory variables were fitted to the plot means of the observed percentages of $N$ and $P$. For the field experiments, it was assumed that main plot errors might be ignored. Treatment effects were tested using $F$ tests for the ratio of the mean deviances. Pairwise differences between treatment means on the logit scale were tested using $t$ tests. Spearmans' rank correlation test was used to compare the responses of the cultivars in the seedling and adult plant stage with the three isolates for both parameters, $N$ and $P$, to estimate the predictive value of observations at either growth stage.

DNA extraction and random amplified polymorphic DNA (RAPD) analysis. To ensure that the observed disease severities were due to the inoculations with isolates IPO001, IPO290, and $I P O 323$, a sample of diseased leaves was taken from each treatment in both field experiments in late August. Conidial cultures of these isolates and those employed to inoculate the field experiment were stored at $-80^{\circ} \mathrm{C}$ for comparison. DNA extraction and RAPD analysis, using primer OPA-20 (GTTGCGATCC, Operon Technologies Inc., Alameda, CA), were conducted according to a protocol that was described previously (17).

\section{RESULTS}

Seedling experiment. Analysis of the seedling experiment data revealed several significant differences between pathogen isolates and host cultivars for both disease parameters, which are summarized in dendrograms (Figs. 1 and 2). Significantly different groups for $N$ and $P$ did not contain the same cultivars or isolates (data not shown) as was observed previously (15). In contrast to the high $N$ levels that were induced by the isolates, the $P$ levels were low in the majority of the cultivars (Table 3 ). This was confirmed in an independent check experiment using the selected subset of three isolates (data not shown).

Field experiment 1992. The crop continued to be green until about 19 days after the first inoculation, which is considerably longer than in the seedling stage, followed by development of necrosis and pycnidia in a relatively short period of time. The responses were considered to be primarily due to the first inoculation, since the RH in the crop upon that inoculation was $>85 \%$ for $82 \mathrm{~h}$, with a 4-h reduction of $\mathrm{RH}$ at $>70 \%$, and a mean temperature of $18^{\circ} \mathrm{C}$, with a minimum and a maximum at 14 and $25^{\circ} \mathrm{C}$,

TABLE 2. Dutch Mycosphaerella graminicola isolates that were employed to study genetic variation for virulence to seedlings and adult plants of 22 wheat cultivars

\begin{tabular}{|c|c|c|}
\hline Isolate & Origin & Year of isolation \\
\hline IPO235 & Anjum, cv. Cebeco 148 & 1972 \\
\hline$I P O 290^{\mathrm{a}}$ & Southern Flevoland, cv. Clement & 1975 \\
\hline IPO281 & Ebelsheerd, cv. Lely & 1975 \\
\hline IPO295 & Nagele, cv. Lely & 1976 \\
\hline IPO304 & Rusthoeve, cv. CB 314 & 1978 \\
\hline$I P O 323^{\mathrm{a}}$ & Western Brabant, cv. Arminda & 1981 \\
\hline IPO333 & Zuidzande, cv. Nautica & 1981 \\
\hline IPO381 & Heerle, cv. Marksman & 1981 \\
\hline IPO394 & 's Heer Arendskerke, cv. Marksman & 1981 \\
\hline IPO439 & Ebelsheerd, cv. Marksman & 1982 \\
\hline IPO89011 & Barendrecht, ? & 1989 \\
\hline$I P O 001^{\mathrm{a}}$ & Ulrum, $\mathrm{F}_{1}$ population & 1991 \\
\hline IPO003 & Ulrum, cv. Obelisk & 1991 \\
\hline IPO006 & Wageningen, cv. Arminda & 1991 \\
\hline
\end{tabular}

a Isolates employed in field experiments. 
respectively. Conditions after the second inoculation were suboptimal, whereas the effect of the third inoculation can be ruled out since the plants developed their symptoms 2 days after it and were sampled only 5 days later. The $N$ and $P$ levels for the different isolates varied widely, and significant cultivar $\times$ isolate interactions for both disease parameters were observed (Table 3). Isolate IPO323 appeared to be a differentiating isolate on the set of cultivars, whereas isolate IPO290 showed a broad virulence. Both isolates were highly aggressive, particularly with respect to $N$, though cultivars Veranopolis, SVP 72017, Carsten V, and Okapi were (relatively) resistant to isolate IPO290. Isolate IPO001 was rather avirulent compared with the aforementioned isolates. The cultivars Vivant, Hereward, Clement, Kavkaz, and Okapi showed significant interactions with the three isolates for $N$ and $P$ and were, therefore, selected for the next field experiment, which was primarily conducted to verify these interactions.

Field experiment 1995. The weather conditions following the first inoculation were particularly conducive to infection by $M$. graminicola. A high natural $\mathrm{RH}$ resulted in a leaf wetness period of $20 \mathrm{~h}$ directly after inoculation, followed by a dry spell of $8 \mathrm{~h}$ and another leaf wetness period for $17 \mathrm{~h}$. The mean temperature during the first $48 \mathrm{~h}$ after inoculation was $21.4^{\circ} \mathrm{C}$. The development of the disease was similar to the 1992 experiment, except that the final disease levels were generally lower, which might have been because of the relatively warm and dry summer (Table 4). The virulence and resistance characteristics were largely similar to the 1992 experiment, and, once more, highly signifi-

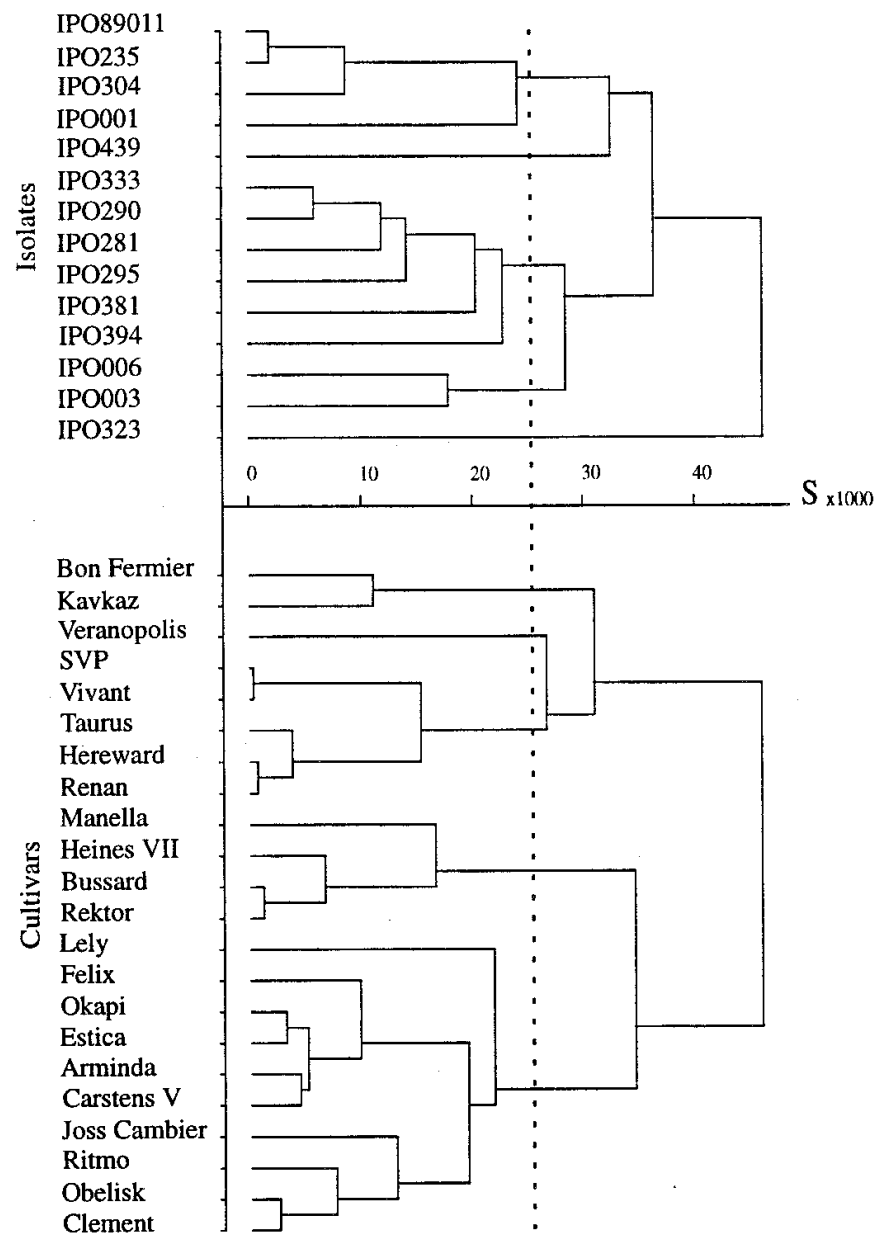

Fig. 1. Dendrograms of 22 wheat genotypes and 14 Mycosphaerella graminicola isolates simultaneously clustered, based on $N$. The positions of the nodes correspond with the cumulative sum of squares for interaction between cultivars and isolates $(S)$ on the horizontal axis. The area to the left of the dotted line represents nonsignificant differences at $=0.05, S=26.5 \times 10^{3}$ (for $=0.01, S=28.4 \times 10^{3}$ ). cant cultivar $\times$ isolate interactions were observed for both disease parameters.

Statistical analyses. The assumption of ignorable main plot errors in the field experiments was checked by fitting the interaction between blocks and isolates as well. Since the $F$ test of the deviance ratio for this interaction was not significant, we concluded that it was unnecessary to maintain a main plot error in the model. The differences in deviance corresponding to the inclusion of individual terms in the model are shown in Tables 5 and 6 .

The $F$ tests for the mean deviance ratio for the cultivar $\times$ isolate interactions in the GLM analyses for both disease parameters in all experiments were highly significant, indicating specificity at both growth stages (Tables 3 to 5). Nonparametric statistical procedures as described by Kema et al. (16) were applied on all data sets and also revealed significant cultivar $\times$ isolate interactions (data not shown). Correlations between $N$ and $P$ for the seedling and adult plant data (pooled for the 1992 and 1995 experiment) were not significant (data not shown), which accords with previous data $(15,16)$.

A joint analysis of the 1995 data and the relevant 1992 data (subset of cultivars similar to the 1995 experiment) was performed to study the year effect (Table 6). The two- and three-way interactions with year (year $\times$ cultivar, year $\times$ isolate, and year $\times$ cultivar $\times$ isolate) were significant for $N$, but not for $P$ (Table 6). Additional statistical analyses of subsets indicated that the significances of these interactions were particularly due to the different response of cultivar Kavkaz to isolate IPO323 and the different performance of isolate IPO001, particularly on cultivar Vivant.

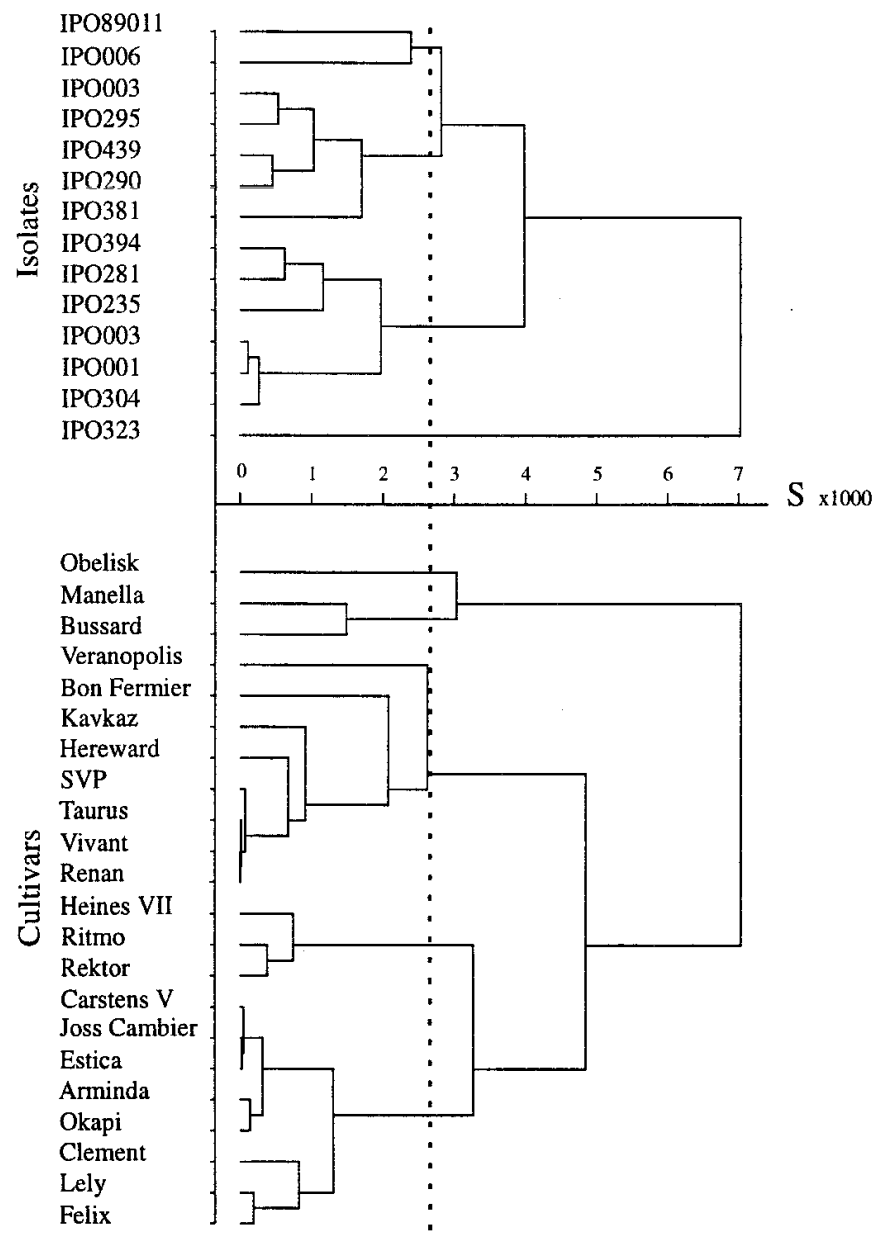

Fig. 2. Dendrograms of 22 wheat genotypes and 14 Mycosphaerella graminicola isolates simultaneously clustered, based on $P$. The positions of the nodes correspond with the cumulative sum of squares for interaction between cultivars and isolates $(S)$ on the horizontal axis. The area to the left of the dotted line represents nonsignificant differences at $=0.05, S=2.6 \times 10^{3}$ (for $=0.01, S=2.8 \times 10^{3}$ ). 
Rank correlations between seedling and adult plant responses for each isolate were only significant for isolates IPO323 and IPO290 (Tables 3 and 7). For $P$, several cultivars such as Lely, Felix, Joss Cambier, Carsten V, and Estica were, in spite of the significance, much more susceptible in the adult than in the seedling stage, a trend that was also observed for the other isolates.

RAPD analyses. The noninoculated controls in both field experiments were virtually free of disease on the flag leaves. Comparative RAPD analyses of isolates from the sporadic lesions on the flag leaves and from the inoculated plots suggested that the lesions on the flag leaves in the noninoculated plots were due to the natural M. graminicola population (Fig. 3). RAPD patterns of isolations from the inoculated plots and the applied inoculum of isolates IPO323, IPO290, and IPO001 were identical (Fig. 3).

\section{DISCUSSION}

The rationale for the current and previous studies $(15,16)$ was to study whether specificity in the wheat- $M$. graminicola pathosys- tem occurs. From seedling data, we recently concluded that specificity is an important characteristic of the pathosystem $(15,16)$. The large cultivar $\times$ isolate interactions in the adult plant stage unequivocally confirmed that conclusion. Until now, virulence studies in M. graminicola did not consider adult plant experiments. Field evaluations of resistance to $M$. graminicola have been conducted and showed substantial differences between cultivars $(4,5,27,30,34)$. However, these studies did not take into account possible genetic differences between pathogen isolates, and, hence, potential interactions between host cultivars and pathogen isolates, since they relied on the application of a single isolate, isolate mixtures, or infections established by heterogeneous natural populations $(4,5,27,29,30,34)$.

The cluster analysis was mainly applied to perform an unprejudiced selection of isolates that showed significantly different virulence characteristics for $N$ and $P$. The suggested genetic differences between the selected isolates IPO323, IPO290, and IPO001 were evidenced by RAPD data and confirmed by the adult plant experiments. Hence, cluster analysis appears to be an

TABLE 3. Comparison of responses, necrosis and pycnidia, in a seedling experiment and an adult plant field experiment comprising 22 wheat cultivars and three Mycosphaerella graminicola isolates that were conducted in 1992 in three and two replications, respectively ${ }^{\mathrm{a}}$

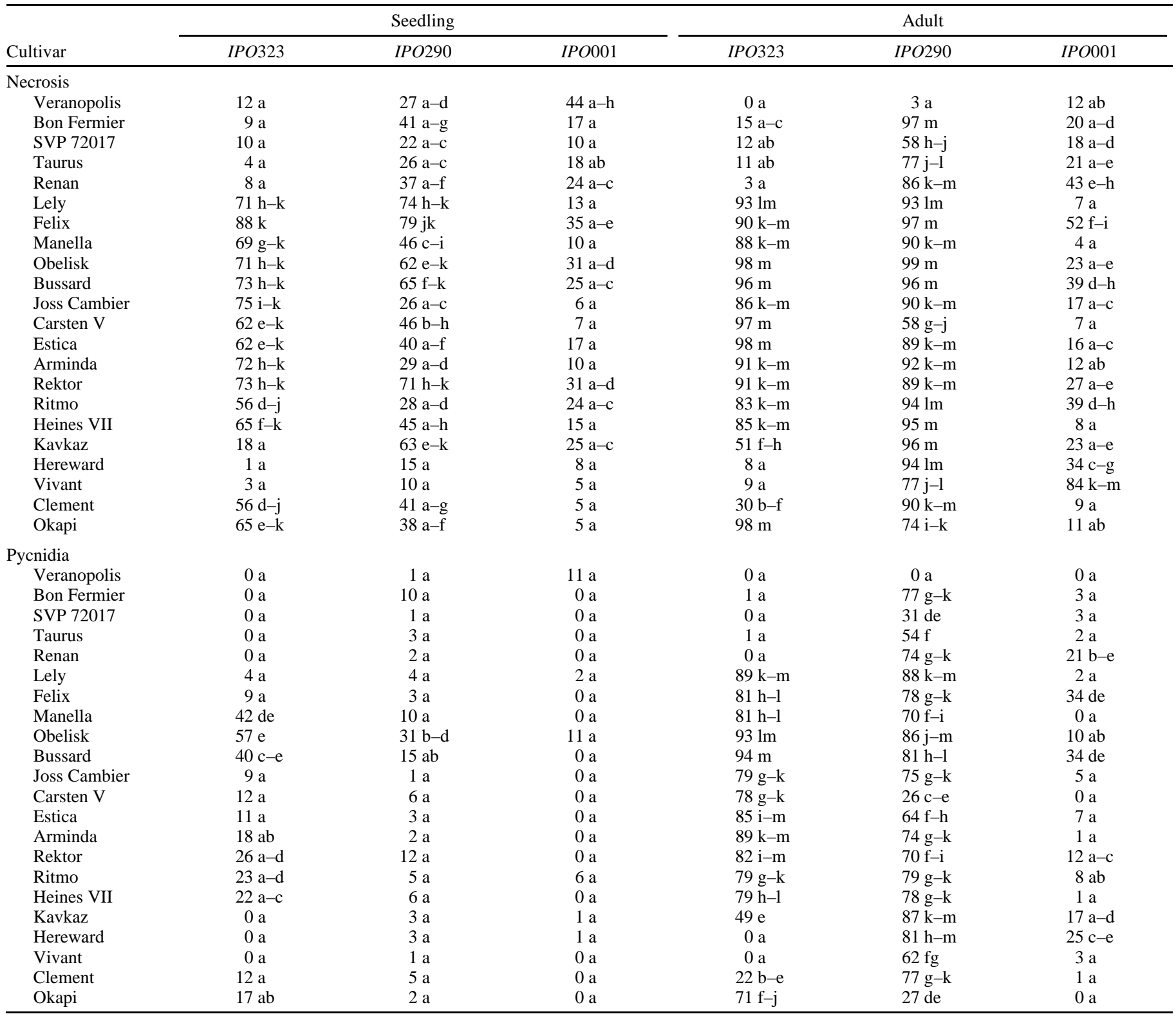

a Figures are backtransformed means of data, percent necrosis and pycnidia, that were averaged over 10 to 15 primary leaves and flag leaves for the seedling and field experiments, respectively. Pairwise comparisons for seedling and adult plant data were performed between all cells on the transformed scale. Significant differences $(P<0.01)$ are indicated by different letters. 
TABLE 4. Responses, necrosis and pycnidia, in an adult plant field experiment comprising five wheat cultivars and three Mycosphaerella graminicola isolates that was conducted in two replications during $1995^{\mathrm{a}}$

\begin{tabular}{lccc}
\hline Cultivar & $I P O 323$ & $I P O 290$ & $I P O 001$ \\
\hline Necrosis & & & \\
Kavkaz & $13 \mathrm{bc}$ & $93 \mathrm{fg}$ & $13 \mathrm{bc}$ \\
Hereward & $4 \mathrm{a}$ & $98 \mathrm{~g}$ & $17 \mathrm{~cd}$ \\
Vivant & $8 \mathrm{abc}$ & $97 \mathrm{fg}$ & $8 \mathrm{ab}$ \\
Clement & $24 \mathrm{de}$ & $99 \mathrm{~g}$ & $7 \mathrm{ab}$ \\
Okapi & $91 \mathrm{f}$ & $79 \mathrm{e}$ & $12 \mathrm{abc}$ \\
Pycnidia & & & \\
Kavkaz & $3 \mathrm{a}$ & $70 \mathrm{de}$ & $1 \mathrm{a}$ \\
Hereward & $0 \mathrm{a}$ & $80 \mathrm{e}$ & $17 \mathrm{~b}$ \\
Vivant & $0 \mathrm{a}$ & $58 \mathrm{~cd}$ & $2 \mathrm{a}$ \\
Clement & $15 \mathrm{~b}$ & $56 \mathrm{~cd}$ & $1 \mathrm{a}$ \\
Okapi & $51 \mathrm{c}$ & $45 \mathrm{c}$ & $1 \mathrm{a}$ \\
\hline
\end{tabular}

a Figures are backtransformed means of data, percent necrosis and pycnidia, that were averaged over 10 flag leaves and analyzed on logit scale. Pairwise comparisons for necrosis and pycnidia were performed on the transformed scale. Significant differences $(P<0.05)$ are indicated by different letters.

TABLE 5. Analyses of deviance of the disease parameters $N$ and $P$ in a seedling experiment and two field experiments

\begin{tabular}{|c|c|c|c|c|}
\hline Change & $\mathrm{df}^{\mathrm{a}}$ & $\begin{array}{c}N \\
\text { mean deviance }\end{array}$ & $\mathrm{df}^{\mathrm{a}}$ & $\begin{array}{c}P \\
\text { mean deviance }\end{array}$ \\
\hline \multicolumn{5}{|l|}{ Seedling experiment ${ }^{b}$} \\
\hline Blocks & 2 & $118^{\mathrm{c}}$ & 2 & $8^{\mathrm{d}}$ \\
\hline Cultivars & 21 & $111^{\mathrm{c}}$ & 21 & $68^{c}$ \\
\hline Isolates & 2 & $852^{\mathrm{c}}$ & 2 & $456^{\mathrm{c}}$ \\
\hline Cultivars $\times$ isolates & 42 & $43^{\mathrm{c}}$ & 42 & $14^{\mathrm{c}}$ \\
\hline Error & 129 & 8 & 129 & 5 \\
\hline \multicolumn{5}{|l|}{ Field experiment $1992^{\mathrm{e}}$} \\
\hline Blocks & 1 & $0^{\mathrm{d}}$ & 1 & $19^{\mathrm{d}}$ \\
\hline Cultivars & 21 & $108^{\mathrm{c}}$ & 21 & $122^{\mathrm{c}}$ \\
\hline Isolates & 2 & $1,696^{\mathrm{c}}$ & 2 & $1,793^{\mathrm{c}}$ \\
\hline Cultivars $\times$ isolates & 42 & $69^{c}$ & 42 & $53^{c}$ \\
\hline Error & 65 & 6 & 65 & 4 \\
\hline \multicolumn{5}{|l|}{ Field experiment $1995^{\mathrm{e}}$} \\
\hline Blocks & 1 & $1^{\mathrm{d}}$ & 1 & $4^{\mathrm{d}}$ \\
\hline Cultivars & 4 & $41^{\mathrm{c}}$ & 4 & $13^{\mathrm{c}}$ \\
\hline Isolates & 2 & $870^{\mathrm{c}}$ & 2 & $492^{c}$ \\
\hline Cultivars $\times$ isolates & 8 & $54^{c}$ & 8 & $45^{\mathrm{c}}$ \\
\hline Error & 14 & 10 & 14 & 2 \\
\hline
\end{tabular}

a $\mathrm{df}=$ degrees of freedom.

${ }^{b}$ A selected subset of the seedling experiment was analyzed that comprised all 22 wheat cultivars, but only three of the 14 Mycosphaerella graminicola isolates.

c $F$ value highly significant $(<0.01)$.

d Not significant.

e The field experiments in 1992 and 1995 comprised 22 and 5 bread wheat cultivars, respectively, inoculated with the three selected Mycosphaerella graminicola isolates.

TABLE 6. Analyses of deviance of the disease parameters $N$ and $P$ to study the year effect in two adult plant field experiments conducted during 1992 and $1995^{\mathrm{a}}$

\begin{tabular}{lcccc}
\hline Change & \multicolumn{1}{c}{$\begin{array}{c}N \\
\mathrm{df}^{\mathrm{b}}\end{array}$} & $\begin{array}{c}\text { mean deviance } \\
\mathrm{df}^{\mathrm{b}}\end{array}$ & $\begin{array}{c}P \\
\text { mean deviance }\end{array}$ \\
\hline Year & 1 & $49^{\mathrm{c}}$ & 1 & $42^{\mathrm{c}}$ \\
Isolate & 2 & $1,191^{\mathrm{c}}$ & 2 & $888^{\mathrm{c}}$ \\
Year $\times$ isolate & 2 & $61^{\mathrm{c}}$ & 2 & $10^{\mathrm{d}}$ \\
Cultivar & 4 & $41^{\mathrm{c}}$ & 4 & $29^{\mathrm{c}}$ \\
Year $\times$ cultivar & 4 & $20^{\mathrm{c}}$ & 4 & $13^{\mathrm{d}}$ \\
Cultivar $\times$ isolate & 8 & $151^{\mathrm{c}}$ & 8 & $125^{\mathrm{c}}$ \\
Year $\times$ cultivar $\times$ isolate & 8 & $22^{\mathrm{c}}$ & 8 & $4^{\mathrm{d}}$ \\
Error & 30 & 3 & 38 & 5 \\
\hline
\end{tabular}

a The selected subset of five wheat cultivars from the experiment in 1992 comprised the same cultivars as the experiment of 1995. Both experiments were inoculated with the same three Mycosphaerella graminicola isolates.

${ }^{\mathrm{b}} \mathrm{df}=$ degrees of freedom.

c $F$ value highly significant $(<0.01)$.

d Not significant. efficient tool to structure large data sets $(6,15)$. In the seedling and adult plant stage, $N$ and $P$ were not necessarily of similar magnitude, which was also demonstrated by these analyses that revealed dissimilarly assembled clusters of isolates or cultivars in dendrograms for $N$ and $P$.

Comparison of seedling and adult plant data revealed some interesting differences. Isolate IPO323 was very different from the other isolates in that it differentiated the cultivars largely in a resistant group and a (moderately) susceptible group at both growth stages. Isolate IPO001 was largely avirulent, particularly in the seedling stage. Isolate IPO290 was fairly avirulent when applied to seedlings, but highly virulent and aggressive toward adult plants. Nevertheless, the rank correlations between seedling and adult plant data for both $N$ and $P$ for isolates IPO323 and IPO290 were significant. In general, adult plants appeared to be more susceptible than seedlings. Our data provide evidence for the specific expression of resistance genes at the seedling stage, but not at the adult plant stage. In wheat-rust pathosystems, some resistance genes are specifically expressed in the adult plant stage, and others are expressed in all growth stages $(23,24)$. Whether genes that control resistance to $M$. graminicola at the seedling stage are also responsible for adult plant resistance to isolate IPO323, as observed in cultivars Bon Fermier, Taurus, Hereward, and Vivant, is not known.

The current evidence for cultivar $\times$ isolate interactions in relatively small field experiments accentuates the genetic variation for virulence in $M$. graminicola. The results of both experiments were largely similar, particularly for $P$. Nevertheless, the disease sever-

TABLE 7. Spearmans' rank correlations between responses ( $N$ and $P$ ) of seedlings and adult plants in 1992 to three Mycosphaerella graminicola isolates

\begin{tabular}{lccc}
\hline & \multicolumn{3}{c}{ Isolates } \\
\cline { 2 - 4 } Parameter & $I P O 323$ & $I P O 290$ & $I P O 001$ \\
\hline$N$ & $0.74 * * \mathrm{a}$ & $0.50^{*}$ & $0.41^{\mathrm{ns}}$ \\
$P$ & $0.78^{* *}$ & $0.45^{*}$ & $0.12^{\mathrm{ns}}$ \\
\hline
\end{tabular}

a $\mathrm{ns}=$ not significant, $* *=$ significant at $P<0.01$, and $*=$ significant at $P<0.05$.

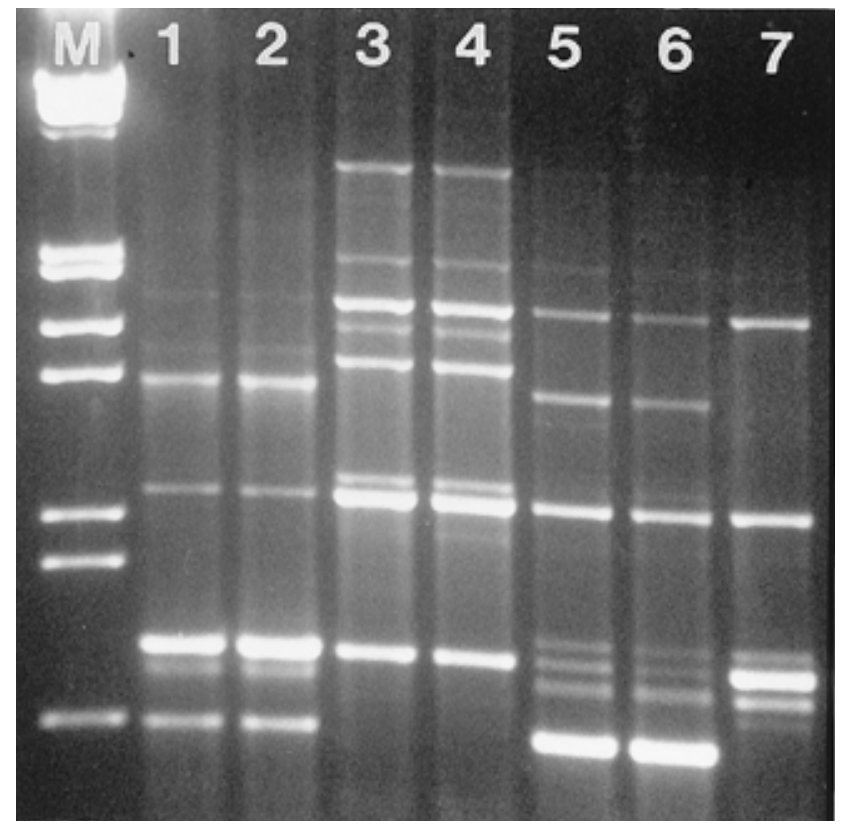

Fig. 3. Polymerase chain reaction products of Mycosphaerella graminicola isolates. M, DNA marker; lane 1, IPO001 inoculum; lane 2, reisolation from field inoculated with IPO001; lane 3, IPO290 inoculum; lane 4, reisolation from field inoculated with IPO290; lane 5, IPO323 inoculum; lane 6, reisolation from field inoculated with IPO323; and lane 7, natural infection from the control plots. 
ities in 1995 were usually lower than in 1992, most clearly exemplified by cultivars Vivant and Kavkaz. Cultivar Vivant responded quite differently with respect to $N$ in the two field experiments. In 1992, it rapidly succumbed after inoculation, whereas, in 1995, it remained largely healthy to isolate IPO001, whereas cultivar Kavkaz responded less to all isolates. At present, we cannot explain these observations, but it is likely that weather conditions played a significant role. Both cultivars may be particularly sensitive to different temperatures, a phenomenon referred to as temperature-sensitive resistance in interactions with other pathogens (24). The significance of the two- and three-way year interactions for $N$ indicated that $P$ is the more reliable parameter for disease assessment, since it appears to be less sensitive to environmental conditions, of which RH is an important component $(7,13,19,31$, 32).

Virulence for the majority of the cultivars was already present in the $M$. graminicola population before these were released. Isolate IPO290 was isolated in 1975 from cultivar Clement, but appeared to be highly virulent toward cultivars Hereward and Vivant. The latter cultivar covered the largest part of the total wheat acreage in the Netherlands from 1993 until 1995. The isolates IPO323, isolated in 1981, and IPO290 were highly virulent toward cultivar Arminda, which was the major Dutch wheat cultivar for almost a decade, with an acceptable level of resistance to $M$. graminicola when it was replaced by newer cultivars with adequate resistance, such as cultivar Obelisk. In contrast, cultivar Obelisk was generally considered susceptible after its commercial life time. Selection pressure extended by a host genotype on a population of $M$. graminicola genotypes apparently results in increased levels of pathogenicity toward that genotype, but obviously takes longer on one cultivar than on the other. Recently, Ahmed et al. (1) provided evidence for the selective influence of host genotypes on $M$. graminicola. Consensus about specificity in the M. graminicola-wheat pathosystem, which was recently discussed by Kema et al. $(15,16)$, was partly hindered by the contradiction between data obtained in experiments and the experience that wheat cultivars had not been reported to unequivocally succumb to new pathotypes of the fungus (14). However, such events are particularly clearly demonstrated in pathosystems with typically qualitative aspects of resistance and virulence. Kema et al. (16) argued that adaptation of $M$. graminicola to resistance in the host might have been overlooked because the process is probably rather slow, due to the characteristics of the pathosystem. The $M$. graminicola-wheat pathosystem appears to be characterized by a combination of quantitative and qualitative aspects of resistance and virulence. Recently, we showed that $M$. graminicola populations are almost continuously capable of completing a sexual cycle (17). The huge genetic diversity of $M$. graminicola populations $(3,15,16,20,21,22)$ is a logical consequence of this observation. Hence, two important aspects of the pathosystem have to be considered to understand the aforementioned contradiction: (i) host cultivars appear to be continuously exposed to extremely diverse populations and (ii) the frequency of pathogen genotypes with virulence characteristics matching resistance in the host will increase at a low rate. The first consideration differs widely from the regular experimental setup in which single isolates or simple mixtures are usually applied $(1,4,7,11,12,15,16,27,36)$. Apart from the fact that wheat cultivars responded differently to isolate mixtures than to single isolates of M. graminicola $(9,38)$, theoretical models have shown that specificity is difficult to prove if isolate mixtures are used $(25,35)$. Hence, the fact that resistance in wheat cultivars does not seem to succumb rapidly to $M$. graminicola is not necessarily an appropriate argument against specificity, particularly since natural $M$. graminicola populations have been observed to be highly heterogeneous $(3,17,20,21,22)$. We suppose, therefore, that the question why interactions as observed in the present and other experiments $(7,11,12,15,16)$ seem to be less evident from farmers' fields is mainly due to (i) the general in- completeness of resistance in the host, which complicates evaluation of increased susceptibility, and (ii) the diversity of natural $M$. graminicola populations, which masks the expression of specific factors.

\section{ACKNOWLEDGMENTS}

We thank E. C. P. Verstappen (IPO-DLO) and D. Yu (Plant Protection Institute, Hubei Academy of Agricultural Sciences, Wuhan, China) for technical assistance, and J. de Bree and P. F. G. Vereijken for statistical help. We thank J. C. Zadoks and an anonymous reviewer for suggestions for improvement.

\section{LITERATURE CITED}

1. Ahmed, H. U., Mundt, C. C., Hoffer, M. E., and Coakley, S. M. 1996. Selective influence of wheat cultivars on pathogenicity of $M y$ cosphaerella graminicola (anamorph Septoria tritici). Phytopathology 86:454-458.

2. Bahat, A., Gelernter, I., Brown, M. B., and Eyal, Z. 1980. Factors affecting the vertical progression of Septoria leaf blotch in short-statured wheats. Phytopathology 70:179-184.

3. Boeger, J. M., Chen, R. S., and McDonald, B. A. 1993. Gene flow between geographic populations of Mycosphaerella graminicola (anamorph Septoria tritici) detected with restriction fragment length polymorphism markers. Phytopathology 83:1148-1154.

4. Brokenshire, T. 1976. The reaction of wheat genotypes to Septoria tritici. Ann. Appl. Biol. 82:415-423.

5. Cooke, B. M., and Jones, D. G. 1971. The epidemiology of Septoria tritici and Septoria nodorum. III. The reaction of spring and winter wheat varieties to infection by Septoria tritici and Septoria nodorum. Trans. Br. Mycol. Soc. 56:121-135.

6. Corsten, L. C. A., and Denis, J. B. 1990. Structuring interaction in twoway tables by clustering. Biometrics 46:207-215.

7. Danon, T., and Eyal, Z. 1990. Inheritance of resistance to two Septoria tritici isolates in spring and winter bread wheat cultivars. Euphytica 47:203-214.

8. Danon, T., Sacks, J. M., and Eyal, Z. 1982. The relationships among plant stature, maturity class, and susceptibility to Septoria tritici leaf blotch of wheat. Phytopathology 72:1037-1042.

9. Eyal, Z. 1992. The response of field-inoculated wheat cultivars to mixtures of Septoria tritici isolates. Euphytica 61:25-35.

10. Eyal, Z., Amiri, Z., and Wahl, I. 1973. Physiologic specialization of Septoria tritici. Phytopathology 63:1087-1091.

11. Eyal, Z., and Levy, E. 1987. Variations in pathogenicity patterns of $M y$ cosphaerella graminicola within Triticum spp. in Israel. Euphytica 36:237-250.

12. Eyal, Z., Scharen, A. L., Huffman, M. D., and Prescott, J. M. 1985. Global insights into the virulence frequencies of Mycosphaerella graminicola. Phytopathology 75:1456-1462.

13. Hess, D. E., and Shaner, G. 1987. Effect of moisture on Septoria tritici blotch development on wheat in the field. Phytopathology 77:220-226.

14. Johnson, R. 1992. Past, present and future opportunities in breeding for disease resistance, with examples from wheat. Euphytica 63:3-22.

15. Kema, G. H. J., Annone, J. G., Sayoud, R., van Silfhout, C. H., van Ginkel, M., and de Bree, J. 1996. Genetic variation for virulence and resistance in the wheat-Mycosphaerella graminicola pathosystem. I. Interactions between pathogen isolates and host cultivars. Phytopathology 86:200-212.

16. Kema, G. H. J., Sayoud, R., Annone, J. G., and van Silfhout, C. H. 1996. Genetic variation for virulence and resistance in the wheat-Mycosphaerella graminicola pathosystem. II. Analysis of interactions between pathogen isolates and host cultivars. Phytopathology 86:213-220.

17. Kema, G. H. J., Verstappen, E. C. P., Todorova, M., and Waalwijk, C. 1996. Successful crosses and molecular tetrad and progeny analyses demonstrate heterothallism in Mycosphaerella graminicola. Curr. Genet. 30:251-258

18. Kema, G. H. J., Yu, D., Rijkenberg, F. H. J., Shaw, M. W., and Baayen, R. P. 1996. Histology of the pathogenesis of Mycosphaerella graminicola in wheat. Phytopathology 86:777-786.

19. Magboul, A. M., Geng, S., Gilchrist, D. G., and Jackson, L. F. 1992. Environmental influence on the infection of wheat by Mycosphaerella graminicola. Phytopathology 82:1407-1413.

20. McDonald, B. A., and Martinez, J. P. 1990. Restriction fragment length polymorphisms in Septoria tritici occur at a high frequency. Curr. Genet. 17:133-138

21. McDonald, B. A., and Martinez, J. P. 1990. DNA restriction fragment length polymorphisms among Mycosphaerella graminicola (anamorph 
Septoria tritici) isolates collected from a single wheat field. Phytopathology 80:1368-1373.

22. McDonald, B. A., Pettway, R. E., Chen, R. S., Boeger, J. M., and Martinez, J. P. 1995. The population genetics of Septoria tritici (teleomorph Mycosphaerella graminicola). Can. J. Bot. 73(suppl.):S292-S301.

23. McIntosh, R. A., Wellings, C. R., and Park, R. F. 1995. Wheat rusts: An atlas of resistance genes. CSIRO Australia, Kluwer Academic Publishers, Dordrecht, the Netherlands.

24. Milus, E. A., and Line, R. F. 1986. Number of genes controlling hightemperature, adult-plant resistance to stripe rust in wheat. Phytopathology 76:93-96.

25. Parlevliet, J. E. 1983. Can horizontal resistance be recognized in the presence of vertical resistance in plants exposed to a mixture of pathogen races? Phytopathology 73:379.

26. Polley, R. W., and Thomas, M. R. 1991. Surveys of diseases of winter wheat in England and Wales, 1976-1988. Ann. Appl. Biol. 119:1-20.

27. Rosielle, A. A. 1972. Sources of resistance in wheat to speckled leaf blotch caused by Septoria tritici. Euphytica 21:152-161.

28. Royle, D. J. 1994. Understanding and predicting epidemics: A commentary based on selected pathosystems. Plant Pathol. 43:777-789.

29. Shaner, G., and Finney, R. E. 1982. Resistance in soft red winter wheat to Mycosphaerella graminicola. Phytopathology 72:154-158.

30. Shaner, G., Finney, R. E., and Patterson, F. L. 1975. Expression and effectiveness of resistance in wheat to Septoria leaf blotch. Phytopathology 65:761-766.

31. Shaw, M. W. 1990. Effects of temperature, leaf wetness and cultivar on the latent period of Mycosphaerella graminicola on winter wheat. Plant Pathol. 39:255-268.

32. Shaw, M. W. 1991. Interacting effects of interrupted humid periods and light on infection of wheat leaves by Mycosphaerella graminicola (Septoria tritici). Plant Pathol. 40:595-607.

33. Shaw, M. W., and Royle, D. J. 1989. Airborne inoculum as a major source of Septoria tritici (Mycosphaerella graminicola) infections in winter wheat crops in the UK. Plant Pathol. 38:35-43.

34. van Beuningen, L. T., and Kohli, M. M. 1990. Deviation from the regression of infection on heading and height as a measure of resistance to Septoria tritici blotch in wheat. Plant Dis. 74:488-493.

35. VanderPlank, J. E. 1982. Host-Pathogen Interactions in Plant Disease. Academic Press, New York.

36. van Ginkel, M., and Scharen, A. L. 1988. Host-pathogen relationships of wheat and Septoria tritici. Phytopathology 78:762-766.

37. Zadoks, J. C., Chang, T., and Konzak, C. 1974. A decimal code for the growth stages of cereals. Weed Res. 14:415-421.

38. Zelikovitch, N., and Eyal, Z. 1991. Reduction in pycnidial coverage after inoculation of wheat with mixtures of isolates of Septoria tritici. Plant Dis. 75:907-910. 